\title{
Current prevalence of latex sensitization in children with spina bifida with use of latex precautions Eric Levey*1, Susan Demetrides ${ }^{1}$, Robert Hamilton ${ }^{2}$ and N Franklin Adkinson ${ }^{2}$
} \author{
Center, Johns Hopkins University School of Medicine, Baltimore, Maryland, USA \\ Email: Eric Levey* - Levey@KennedyKrieger.org \\ * Corresponding author \\ from $\left.5\right|^{\text {st }}$ Annual Meeting of the Society for Research into Hydrocephalus and Spina Bifida \\ Heidelberg, Germany. 27-30 June 2007 \\ Published: 20 December 2007 \\ Cerebrospinal Fluid Research 2007, 4(Suppl I):SI3 doi:I0.II86/I743-8454-4-SI-SI3
}

Address: ${ }^{1}$ Keelty Center for Spina Bifida, Kennedy Krieger Institute and Asthma, Baltimore, Maryland, USA and ${ }^{2}$ Allergy Center, Bayview Medical

This abstract is available from: http://Www.cerebrospinalfluidresearch.com/content/4/SI/SI3

(c) 2007 Levey et al; licensee BioMed Central Ltd.

\section{Background}

Children with spina bifida (SB) historically were found to have high rates (up to 50\%) of latex sensitization and allergy believed due to repeated high-risk exposures including surgeries and catheterization. Latex allergy can in some cases be life-threatening and certainly impacts quality of life. Since the association between SB and latex has been substantiated, most SB Centers have begun using latex avoidance measures with presumed lower rates of sensitization. Objective: The purpose of this study is to evaluate the prevalence of latex sensitization and allergy in a population of children with spina bifida that was born after the institution of latex avoidance measures, and to assess associated risk factors for latex sensitization.

\section{Materials and methods}

Individuals with spina bifida, age 0 to 18 years, are being recruited from a regional SB Center during routine clinic appointments. Study participants complete a latex allergy questionnaire regarding demographics, history of allergy, number of surgeries, and use of CIC. A blood sample is obtained for measurement of latex-specific IgE, total IgE, and two multi-allergen screens, one detects IgE antibody to 15 common aeroallergens (Phadiatop) and the other, IgE to the 5 foods (milk, egg, soy, wheat, and peanut) that cause most food sensitivities in children (FX5).

\section{Results}

$\mathrm{N}=35$, mean age 7.8 years, range 0.3 to 17 years. Of the 35 patients tested, $5(14 \%)$ tested positive for latex-specific IgE. One child was 6.5 years old and had her initial surgery in United Arab Emirates without latex precautions. The other 4 children who were sensitized to latex were 10 years of age or older. All 5 latex IgE positive individuals had total IgE levels that were significantly elevated $(>200 \mathrm{U} / \mathrm{mL}$ ). There was no statistically significant relationship between positive Phadiatop or FX5 and positive latex IgE. Positive latex IgE was statistically associated with black race $(p=0.006)$ but was not associated with gender, number of surgeries, CIC, or history of atopy or food allergy.

\section{Conclusion}

The prevalence of latex sensitization has decreased substantially with the use of latex avoidance measures. None of the 19 children under 10 years of age who were born in the U.S. had detectable latex-specific IgE. The relationship between race and latex sensitization needs to be explored further. The study may be underpowered to detect an actual relationship between latex sensitivity and some risk factors. We are continuing to recruit study participants. 